\title{
Mobile, one stage, bilateral ear surgery for chronic otitis media patients in remote areas
}

\author{
P Homøe, H C Florian Sørensen*, M Tos $\dagger$
}

\begin{abstract}
Objectives: We evaluated the results of mobile, one stage, bilateral ear surgery conducted in Greenland, where chronic otitis media with and without suppuration is prevalent. The study aimed to increase the number of operations conducted and to reduce the cost of ear surgery in remote areas.

Materials and methods: The study was longitudinal and prospective, with a two-year follow up. Seventeen East Greenlandic patients with bilateral chronic suppurative otitis media or chronic otitis media were selected. Their median age was 16 years; 53 per cent were female and 47 per cent male. Hearing was assessed using median air conduction pure tone average gain, and the 'take rate' (i.e. the percentage of total ears with a closed perforation) was evaluated.

Results: All patients attended for follow up. Eighty-two per cent had at least one perforation closed, and the overall take rate was 65 per cent of the 34 ears. The median air conduction pure tone average gain after two years was $18 \mathrm{~dB}$ and $13 \mathrm{~dB}$ for the right and left ears, respectively. Fourteen patients (82 per cent) obtained an air conduction pure tone average hearing level of $\leq 25 \mathrm{~dB}$ in at least one ear. In total, 71 per cent of the patients were satisfied. There were no hearing hazards.

Conclusions: The results of mobile, one stage, bilateral ear surgery conducted in Greenland for long-lasting chronic suppurative otitis media and chronic otitis media were acceptable and safe, and more ears underwent surgery at reduced cost compared with unilateral ear surgery.
\end{abstract}

Key words: Otitis Media; Myringoplasty; Tympanic Membrane Perforations; Otologic Surgical Procedures; Developing Countries

\section{Introduction}

Around the world, ear surgery is generally performed in tertiary care settings. In most developing countries and in many remote areas, access to tertiary care and to ear surgery is limited, even though chronic otitis media may be highly prevalent. $^{1-5}$ Thus, the provision of mobile ear surgery units which bring surgeons to such areas may enable improved surgical ear care, even if the results are somewhat poorer than those from tertiary units. ${ }^{6-9}$ Many ENT patients in such areas are in need of ear surgery either to improve hearing, to stop ear discharge or to enable the use of hearing aids. It is important to treat as many patients as possible, and also to reduce treatment costs.

Recently, reports from two state-of-the-art tertiary units conducting one stage, bilateral ear surgery for small, uncomplicated, dry tympanic membrane perforations have shown acceptable, safe results without any iatrogenic sensorineural hearing injury. ${ }^{10-13}$ However, these studies did not assess large-sized perforations due to long-lasting chronic otitis media or chronic suppurative otitis media (CSOM), which are often seen in populations at high risk of otitis media (including those in Greenland). ${ }^{1-5}$ Beal et al. reported the surgical results of a mobile ear surgery unit serving the indigenous population of the Bethel area in Alaska. ${ }^{6}$ The report mentioned that bilateral ear surgery was performed in some patients, but the results were not specified.

The population of Greenland is 55000 . There are 16 healthcare districts, each housing a small hospital with an operating theatre and sterilisation facilities. Recently, mobile ear surgery units have been introduced in Greenland and acceptable results have been reported, even where access to continued, specialised care is minimal. ${ }^{9}$ However, as bilateral ear disease is present in almost one-third of the approximately 4000 Greenlanders with chronic otitis media and CSOM, we decided to introduce bilateral ear surgery in order to increase the number of operated ears, and thereby also to reduce the cost per ear operated upon. 
The aims of this study were to report the short- and long-term surgical and hearing results of mobile, one stage, bilateral ear surgery in patients with longlasting chronic otitis media and CSOM who lived in remote areas of Greenland.

\section{Patients and methods}

The study was prospective and longitudinal and was carried out in the small town of Tasiilaq, in East Greenland, from 2004 to 2006.

The travelling ear surgery team consisted of an experienced ear surgeon (the last author), a theatre nurse, an anaesthetist and an anaesthetics nurse. The equipment used has been described elsewhere. ${ }^{9}$ The surgery was carried out over three weeks in July and August 2004. We planned two one stage, bilateral operations under general anaesthesia per day, mainly due to limitations in sterilisation capacity.

The patients were selected from a waiting list previously prepared by travelling ENT specialists who assessed patients' CSOM and chronic otitis media and their severity of hearing loss. Children younger than eight years and persons suspected of cholesteatoma or otosclerosis were not included.

Pre-operatively, the surgeon took a history and examined the patient, assisted by an interpreter.

The local ethics committee did not find approval necessary, but all patients gave oral, informed consent.

The most severely affected ear was operated upon first; the other ear was operated upon during the same general anaesthesia session. Patients were discharged the day after surgery with instructions on post-operative care. Sutures were removed after one week.

Follow-up examinations were performed by the first author three weeks and two years after surgery, independently of the ear surgeon. Hearing tests were performed in quiet rooms, but without access to silent booths or the facility for reliable measurement of bone conduction. Audiometry results were therefore recorded as air conduction pure tone average (PTA) values for 500, 1000 and $2000 \mathrm{~Hz}$. Otomicroscopy was undertaken during follow-up examinations. Cleaning of the ear canal was performed with a portable suction aid.

\section{Definitions}

Chronic suppurative otitis media was defined as an ear with evidence of chronic tympanic membrane perforation persisting for several years, with present or intermittent otorrhoea.

Chronic otitis media was defined as an ear with evidence of chronic dry tympanic membrane perforations persisting for several years.

\section{Statistical analysis}

Data were processed using the Statistical Package for the Social Sciences version 15 for Windows software. Values are given as medians, quartiles and ranges. The Wilcoxon signed rank test was used to test the difference between the paired variables of pre- and post-operative hearing results. Test results were twosided, and the level of significance was set at $p \leq 0.05$.

\section{Results}

The median age of the 17 patients was 16 years (range: eight to 38 years); nine (53 per cent) were female and eight (47 per cent) male. All patients attended for follow up: one was seen after one year, 15 were seen after two years and one (who had moved to West Greenland) was seen after four years.

\section{Pre-and peri-operative findings and surgical techniques}

Four patients had bilateral CSOM, four patients had CSOM in one ear and chronic otitis media in the other, and nine patients had bilateral chronic otitis media.

Patients with suppuration prior to surgery were treated with topical eardrops containing ciprofloxacin and hydrocortisone; some also received additional oral dicloxacillin prior to the operation and this was continued for 8 to 10 days after surgery.

Type one tympanoplasty or myringoplasty using temporalis muscle fascia grafting as either onlay or underlay was applied in five patients (10 ears; 29 per cent) with subtotal or smaller perforations. In the remaining 12 patients ( 24 ears) (71 per cent) having total or almost total perforations, we used a cartilage palisade technique, harvesting unilaterally from the concha of the pinna. One operation was a repeat procedure via a retroauricular approach; all other patients were operated upon via an end-aural approach.

Sixteen of the ears had total pars tensa perforations, usually bilaterally. Subtotal (central) perforations were found in 18 ears, and 16 of these were anterior or inferior.

Gelfoam impregnated with antibiotics was used for the tympanic cavity, while the external ear canal was packed with Gelfoam and two pieces of gauze impregnated with hydrocortisone, terramycin and polymyxin B for approximately three weeks. Some ears were tightly packed, while others were packed lightly to enable some air passage and sound transmission.

Mastoidectomy and ossiculoplasty were not performed. No cholesteatomas or early complications were found.

\section{Two- to three-week follow up}

Two patients from a town far to the north were seen for treatment control two weeks' post-operatively, because they had to fly home. One was seen to be without perforations, after cleaning the ear canals. The other patient still had Gelfoam covering the palisades and so their result could not be determined. At two-year follow up, both these patients had intact tympanic membranes bilaterally.

Of the remaining 15 patients, who were seen three weeks post-operatively, only four (27 per cent) were healed bilaterally, three of whom had been grafted with temporalis muscle fascia. Five (33 per cent) 
TABLE I

RESULTS OF 17 ONE STAGE, BILATERAL EAR OPERATIONS FOR CSOM OR COM IN GREENLANDIC PATIENTS, AT FOLLOW UP

\begin{tabular}{lc}
\hline Status & $n(\%)$ \\
\hline Presented & $17^{*}(100)$ \\
Bilateral closure & $8(47)$ \\
Unilateral closure & $6(35)$ \\
At least one closed perforation & $14(82)$ \\
Intermittent discharge & $7(41)$ \\
Overall closure (ears) $^{\dagger}$ & $22(65)$ \\
Intermittent discharge (ears) $^{\dagger}$ & $8(24)$ \\
Complications $^{\dagger}$ & $1(6)$ \\
\hline
\end{tabular}

*Fifteen patients were seen at two years' follow up, one at one year and one at four years. ${ }^{\dagger} n=34$ ears. CSOM $=$ chronic suppurative otitis media; $\mathrm{COM}=$ chronic otitis media

were not healed in either ear, while six ( 40 per cent) were unilaterally healed. Thus, of a total of 34 ears, 16 (47 per cent) were healed two to three weeks postoperatively. Of the unhealed tympanic membranes, six perforations were only a few millimetres wide. Four patients were treated with prolonged application of impregnated gauze, while all others with perforations were treated with topical eardrops for an additional seven days. Bilateral packing of the ear canal was not reported to be a problem.

\section{Late follow up}

The surgical outcomes of the 17 bilateral operations are shown in Table I. We found post-operative fluctuation between intact and perforated tympanic membranes in 10 ( 66 per cent) of the 15 patients in whom ear status was assessed at both three weeks and two years post-operatively (see Table II). Most perforations seen at late follow up were considerably smaller than those seen pre-operatively. There was no difference in closure rate assessed at late follow up, comparing patients undergoing the cartilage palisade technique with those undergoing the temporalis muscle fascia technique (16/24 (67 per cent) and six of 10 (60 per cent), respectively).

All 17 patients underwent a post-operative hearing test at late follow up. Fourteen ( 82 per cent) had an air conduction PTA hearing level of $\leq 25 \mathrm{~dB}$ in at least one ear. One patient had undergone no pre-operative hearing test; however, this patient's air conduction PTA results at one-year follow up were 10 and $13 \mathrm{~dB}$, for the respective ears.

\section{TABLE II}

TYMPANIC MEMBRANE STATUS IN 15 GREENLANDIC PATIENTS UNDERGOING ONE STAGE, BILATERAL EAR SURGERY FOR CSOM OR COM, AT 3-WEEK AND 2-YEAR FOLLOW UP

\begin{tabular}{lcc}
\hline TM status at 3 wks & \multicolumn{2}{c}{ TM status at 2 yrs } \\
\cline { 2 - 3 } & Intact $(n(\%))$ & Perforated $(n(\%))$ \\
\hline Intact & $11(37)$ & $7(23)$ \\
Perforated & $6(20)$ & $6(20)$ \\
\hline
\end{tabular}

Data refer to a total of 30 operated ears. $\mathrm{CSOM}=$ chronic suppurative otitis media; $\mathrm{COM}=$ chronic otitis media; $\mathrm{TM}=$ tympanic membrane; wks = weeks; yrs = years
TABLE III

AC PTA RESULTS BEFORE AND 2 YEARS AFTER ONE STAGE, BILATERAL EAR SURGERY IN 15 GREENLANDIC PATIENTS WITH CSOM OR COM

\begin{tabular}{lccc}
\hline Ear & Pre-op & 2 yrs post-op & $p^{*}$ \\
\hline Right & $41(30-45)$ & $21(15-32)$ & $<0.008$ \\
Left & $39(27-45)$ & $26(14-32)$ & $<0.007$
\end{tabular}

Data represent median $(25-75 \%$ quartile) values in $\mathrm{dB}$. *Wilcoxon signed rank test, comparing dependent variables within two groups. AC PTA = air conduction pure tone average (average of 500, 1000 and $2000 \mathrm{~Hz}$ ); $\mathrm{CSOM}=$ chronic suppurative otitis media; $\mathrm{COM}=$ chronic otitis media; pre-op = pre-operative; post-op = post-operative

Pre-operative and two-year post-operative hearing tests were available for 15 patients; these patients' air conduction PTA results improved significantly in both ears (see Table III). In 13 out of these 15 (87 per cent), a gain in air conduction PTA was observed two years post-operatively. The hearing gains were bilateral in all but two patients, whose air conduction PTA hearing levels showed little change in one ear but improvement in the other. Pre-operatively, all 15 patients had air conduction PTA levels of $>20 \mathrm{~dB}$ in both ears. After two years, nine ( 60 per cent) of these patients had levels of $\leq 20 \mathrm{~dB}$ in at least one ear. At two-year follow up, the median air conduction PTA hearing gain for the individual ears was $18 \mathrm{~dB}$ for the right ears (25 and 75 per cent quartiles: 10 and $23 \mathrm{~dB}$; range: -22 to $+37 \mathrm{~dB})$ and $13 \mathrm{~dB}$ for the left ears $(25$ and 75 per cent quartiles: 7 and $21 \mathrm{~dB}$; range: -15 to $+40 \mathrm{~dB}$ ), compared with pre-operative values.

Two patients showed a bilateral deterioration in air conduction PTA hearing levels (being -15 and $-22 \mathrm{~dB}$, and -6 and $-8 \mathrm{~dB}$, for the respective ears). These hearing losses were conductive, and both the patients were found to have large, bilateral re-perforations at two-year follow up.

No patients showed any clinical signs of sensorineural hearing catastrophes.

At late follow up, all 17 patients were questioned on their satisfaction with their ear surgery, and all responded. Twelve (71 per cent) were satisfied, one (6 per cent) was not satisfied and four ( 24 per cent) were unsure.

One patient developed a unilateral cholesteatoma and was referred for further surgery.

\section{Discussion}

Many ear surgeons question the wisdom of one stage, bilateral ear surgery for chronic otitis media and CSOM, because of the potential risk of subsequent sensorineural hearing loss and even deafness. Studies conducted in the 1970s and 1980s reported this risk to be $1.2-4.5$ per cent; a more recent study reported that 1.3 per cent of 2224 patients with normal pre-operative bone conduction showed evidence of sensorineural hearing loss following middle-ear surgery. ${ }^{14,15}$ These same studies reported the risk of post-operative deafness to be between 0.2 and 0.5 per cent. Thus, the risk of disaster during ear surgery is agreed to be very low. Two recent studies 
TABLE IV

EAR SURGERY FOR COM IN COMPARABLE REMOTE LIVING POPULATIONS: COMPARISON OF RESULTS FROM CANADA, ALASKA AND AUSTRALIA

\begin{tabular}{|c|c|c|c|c|c|}
\hline \multirow[t]{2}{*}{ Study } & \multicolumn{2}{|c|}{ Patients } & \multicolumn{2}{|c|}{ Follow up } & \multirow[t]{2}{*}{ TM closure (\%) } \\
\hline & $n$ & Age & Rate (\%) & Duration (yrs) & \\
\hline Beal et al. ${ }^{17}$ & 1104 & School children & 31 & 1 & 77 \\
\hline Brodovsky et al. ${ }^{18}$ & 123 & School children & 91 & $>0.5$ & 60 \\
\hline Tower ${ }^{19}$ & 664 & Children & 89 & 10 & 61 \\
\hline Beal et al. ${ }^{6 *}$ & 140 & All ages & 82 & 1 & 84 \\
\hline McCullough et al. ${ }^{20}$ & 274 & All ages & 82 & $0.5-1$ & 70 \\
\hline Orr \& McCullough ${ }^{21}$ & 71 & 12 yrs & 100 & 2 & 58 \\
\hline Bretlau et al. ${ }^{22}$ & 221 & $5-62$ yrs & 46 & $>2$ & 39 \\
\hline Duval et al. ${ }^{23}$ & 143 & School children & 65 & $>2$ & 61 \\
\hline Mak et al. ${ }^{24 \dagger}$ & 273 & $4-67$ yrs & 43 & $>0.5$ & 67 \\
\hline Homøe et al. ${ }^{16}$ & 274 & $8-60 \mathrm{yrs}$ & $75,61^{*}$ & 2 & $72,78^{\ddagger}$ \\
\hline Present study & 17 & $8-36$ yrs & 100 & 2 & $65^{* *}, 82^{\#}$ \\
\hline
\end{tabular}

Adapted with permission. ${ }^{9}{ }^{*}$ Some patients had bilateral ear surgery. ${ }^{\dagger}$ Australian Aboriginal patients. ${ }^{*}$ Results for 1 -year and 2 -year follow up. ${ }^{* *}$ Percentage of total ears with closed perforations. ${ }^{*}$ Percentage of patients with at least one closed perforation. COM $=$ chronic otitis media; TM = tympanic membrane; yrs = years

conducted under optimal clinical conditions in state-of-the-art tertiary units, which assessed one stage, bilateral ear surgery with myringoplasty or type one tympanoplasty in selected patients with relatively simple tympanic membrane defects in dry ears, both reported acceptable success rates (as indicated both by bilateral closure rate of perforations (72-94 per cent) and by bilateral closure of airbone gap to within $20 \mathrm{~dB}(60-100$ per cent $)) .^{10-13}$

The advantages of one stage, bilateral procedures include, most notably, the reduced cost of ear surgery per ear and the greater numbers of ears which can be operated upon, but also the requirement to harvest graft material from only one side. The disadvantages of these procedures are the prolonged operation time and the need for three weeks' bilateral ear packing post-operatively. However, the latter is reported to represent only a minor problem. ${ }^{13}$ Accordingly, bilateral ear surgery may be advantageous to populations with a high prevalence of chronic ear disease and limited access to ear surgery, such as in Greenland.

Our group published recently the results of 274 cases of unilateral ear surgery for chronic otitis media and CSOM carried out in a mobile setting in Greenland. ${ }^{9,16}$ Two or (at most) three patients (i.e. two or three ears) were operated upon per day. The study showed a long-term 'take rate' (i.e. the percentage of total ears with closed perforations) of 76 per cent and a long-term median air conduction PTA hearing gain of $12 \mathrm{~dB} .^{9,16}$

In the present study, which we believe is the first to report results for one stage, bilateral ear surgery conducted by a mobile surgical unit in remote areas, we operated upon a minimum of two patients (i.e. four ears) per day, thus increasing the number of ears operated upon by $25-50$ per cent.

Also, this was the first study to report results for the cartilage palisade technique in patients with small inferior tympanomeatal angles, often seen in Greenlanders (compared with Danish patients).

Our overall long-term take rate was only 65 per cent of operated ears; however, 82 per cent of patients had either one or both perforations closed, and the long-term median air conduction PTA hearing gain was $18 \mathrm{~dB}$ on the best side. Furthermore, most of the perforations observed at late follow up were considerably smaller than those seen before surgery.

The patients in our two studies are comparable, and the results of the present study are thus acceptable (although there is of course room for improvement). Table IV shows the results of ear surgery for chronic otitis media and CSOM in Inuit populations from Canada and Alaska, in an Australian Aboriginal population, and in the present study's population. It can be seen that the tympanic membrane closure rates are rather low when considering the total operated ears, but acceptable when considering the number of patients with at least one perforation closed. All but two of these comparable studies were performed at tertiary hospital units. ${ }^{6,9,17-24}$ Other studies assessing mobile ear surgery in remote areas of Mexico and Namibia have reported success rates of 61 to 84 per cent. $^{7,8}$

Overall, the presented results are not comparable to those obtained from state-of-the-art tertiary centres. This was due especially to the more severe, chronic (and in many cases tympanosclerotic) state of the ears in our study population, and also to the impossibility of close specialist follow up postoperatively. In addition, our hearing tests did not comply with the usual standards and recommendations, and the results are therefore not comparable with post-operative hearing results from well equipped tertiary units. ${ }^{25}$ Our hearing test results are however comparable to those of studies performed in similar circumstances. We found satisfying, long-term improvement in air conduction PTA results. We also found no evidence of sensorineural hearing loss due to ear surgery.

Another notable finding of the present study was the high degree of post-operative fluctuation between intact and perforated tympanic membranes. This was also evident in our previous studies in Greenland, emphasising the importance of long-term follow up.' 
Where possible, we tried to avoid massive packing of the external ear canals; despite this, most patients were packed completely and bilaterally. However, no patients objected to this. Two years after surgery, we asked whether patients were satisfied with their operations; 71 per cent stated that they were. Only one patient reportedly being unsatisfied, the stated reasons being persistent, intermittent discharge and less hearing improvement than expected. The rate of satisfaction for our previous study in Greenland was comparable, at 73 per cent. ${ }^{9}$

The only complication we detected was cholesteatoma development in one patient, and this could not be related to the patient's bilateral surgical procedure.

Some authors recommend the cartilage palisade technique for the repair of especially large tympanic membrane perforations. ${ }^{26} \mathrm{We}$ found that the closure rate for this technique (67 per cent) was not significantly better than that for the temporalis muscle fascia technique (60 per cent), and certainly no better than that for the fascia technique used in our previous study of unilateral ear surgery in Greenland (in which the closure rate for total perforations was 15 out of 18 (83 per cent) after two years' follow up). ${ }^{9}$ Cartilage palisades may be covered with fascia or perichondrium on the external ear canal side and may prevent a perforation between two palisades, particularly in ears with slightly moist middle-ear mucosa, a common finding among Greenlandic patients. $^{27,28}$ This may improve the closure rate.

- This study assessed one stage, bilateral ear surgery for chronic otitis media, conducted by a mobile ear surgery unit in remote areas; such results have not previously been reported

- The overall graft 'take-rate' (i.e. percentage perforation closure) was 65 per cent of a total of 34 ears

- Seventy-one per cent of patients were satisfied, and there were no hearing hazards

- Mobile, one stage, bilateral ear surgery for large, bilateral tympanic membrane perforations, conducted in remote areas without optimal surgical facilities, is safe and has acceptable results

\section{Conclusion}

This study shows that mobile, one stage, bilateral ear surgery for chronic otitis media and CSOM, conducted in remote areas without optimal surgical facilities, is safe and has acceptable results. The success of surgery was comparable to that of unilateral ear surgery conducted in the same circumstances. We therefore recommend one stage, bilateral surgery for even large-sized perforations, using myringoplasty or type one tympanoplasty, but not when performing ossiculoplasty or cholesteatoma procedures. The advantage of one stage, bilateral surgery is that more ears can be operated upon for a cost comparable to that of unilateral surgery. This is very important for populations in remote areas and developing countries which have a high prevalence of chronic otitis media and CSOM and no easy access to tertiary ear surgery units. The provision of economical, mobile ear surgery facilities may in turn help to improve conditions for hearing rehabilitation in these populations.

\section{Acknowledgements}

We wish to thank the local physicians and healthcare staff in Tasiilaq, especially the audiometrist.

\section{References}

1 Acuin J. Chronic Suppurative Otitis Media: Burden of Illness and Management Options. In: Child and Adolescent Health and Development Prevention of Blindness and Deafness: World Health Organization, Geneva, Switzerland. 2004;1-84

2 Sunderman J, Dyer H. Chronic ear disease in Australian Aborigines. Med J Aust 1984;140:708-11

3 Baxter JD. Clinical research in the Canadian North. Acta Otolaryngol (Stockh) 1983;95:615-19

4 Homøe P, Christensen RB, Bretlau P. Prevalence of otitis media in a survey of 591 unselected Greenlandic children. Int J Pediatr Otorhinolaryngol 1996;36:215-30

5 Minja BM, Moshi NH, Ingvarsson L, Bastos I, Grenner J. Chronic suppurative otitis media in Tanzanian school children and its effects on hearing. East Afr Med J 2006;83: $322-5$

6 Beal DD, Nathanson SE, Chandler L, Springer S. Results of a surgical, otologic program in a remote Eskimo population. Alaska Medicine 1981;23:10-12

7 Barrs DM, Muller SP, Worrndell DB, Weidmann EW. Results of a humanitarian otologic and audiologic project performed outside the United States: lessons learned from the "Oye, Amigos!" project. Otolaryngol Head Neck Surg 2000;123:722-7

8 Lehnerdt G, van Delden A, Lautermann J. Management of an "Ear Camp" for children in Namibia. Int J Pediatric Otorhinolaryngol 2005;69:663-8

9 Homøe P, Siim C, Bretlau P. Outcome of mobile ear surgery for chronic otitis media in remote areas. Otolaryngol Head Neck Surg 2008;139:55-61

10 Mitchell RB, Pereira KD, Younis RT, Lazar RH. Bilateral fat graft myringoplasty in children. Ear Nose Throat J 1996; 75:652-6

11 Sakagami M, Mishiro Y, Tsuzuki K, Seo T, Sone M. Bilateral same day surgery for bilateral perforated chronic otitis media. Auris Nasus Larynx 2000;27:35-8

12 Katsura H, Sakagami M, Tsuji K, Muto T, Okunaka M, Mishiro Y et al. Reevaluation of bilateral same-day surgery for bilateral perforated chronic otitis media. Otol Neurotol 2005;26:842-5

13 Caye-Thomasen P, Nielsen TR, Tos M. Bilateral myringoplasty in chronic otitis media. Laryngoscope 2007;117: 903-6

14 Tos M, Lau T, Plate S. Sensorineural hearing loss following chronic ear surgery. Ann Otol Rhinol Laryngol 1984;93: 403-9

15 Völter C, Baier G, Schön F, Müller J, Helms J. Inner ear depression after middle ear interventions [in German]. Laryngorhinootologie 2000;79:260-5

16 Homøe P, Nikoghosyan G, Siim C, Bretlau P. Hearing outcome after mobile ear surgery for chronic otitis media in Greenland. Int J Circumpolar Health 2008;67:452-60

17 Beal DD, Stewart KC, Fleshman JK. The surgical program to reduce the morbidity of chronic otitis media in the Alaska native. Acta Soc-Med Scand 1972;6:259-65 
18 Brodovsky D, Woolf C, Medd LM, Hildes JA. Chronic otitis media in the Keewatin district. In: Shephard RJ, Itoh S, eds. Proceedings of the IIIrd International Symposium on Circumpolar Health. Toronto and Buffalo: University of Toronto Press, 1976;398-402

19 Tower EA. Otitis media surgery - long term effects. In: Harvald B, Hansen JPH eds. Proceedings of 5th International Symposium on Circumpolar Health, Copenhagen 1981. Nordic Council for Arctic Medical Research, 1982; $360-3$

20 McCullough D. Tympanoplasty results in the Canadian Arctic 1970-1980. In: Harvald B, Hansen JPH, eds. Proceedings of 5th International Symposium on Circumpolar Health, Copenhagen 1981. Nordic Council for Arctic Medical Research, 1982;364-5

21 Orr PH, McCullough DW. Follow-up of tympanoplasties in three N.W.T. communities 1975-80. Circumpolar Health 1984:241-4

22 Bretlau P, Kirkegaard J, Thomsen KA et al. Kronisk otitis media i nutidens Grönland (In Danish). In: Kern P, Cordtz T, eds. Nuna Med 91-en grönlandskmedicinsk konference. Nuuk, Offset, Greenland, 1991:136-8

23 Duval L, MacDonald S, Lugtig L, Mollins J, Tate R. Otitis media in the Keewatin: 20 years of experience 1970-1991. Arct Med Res 1994;53(suppl 2):676-9

24 Mak D, MacKendrick A, Weeks S, Plant AJ. Middle-ear disease in remote Aboriginal Australia: a field assessment of surgical outcomes. J Laryngol Otol 2000;114:26-32

25 Committee on Hearing and Equilibrium guidelines for the evaluation of results of treatment of conductive hearing loss. Otolaryngol Head Neck Surg 1995;113:186-7
26 Dornhoffer J. Cartilage tympanoplasty: indications, techniques and outcome in a 1,000-patient series. Laryngoscope 2003;113:1844-56

27 Wiegand H. Tympanic membrane repair with cartilage and double tissue-layered grafts [in German]. HNO 1978 26:233-6

28 Ferekidis AE, Nikolopoulos TP, Kandiloros CK, Ferekidou EE, Yiotakis JE, Tsangaroulakis A et al. Chondrotympanoplasty: a modified technique of cartilage graft tympanoplasty. Med Sci Monit 2003;9:73-8

Address for correspondence:

Dr Preben Homøe,

Associate Professor

Department of Otolaryngology, Head and Neck Surgery, F 2071, Rigshospitalet,

University Hospital of Copenhagen,

Blegdamsvej 9, DK-2100 Ø,

Denmark.

Fax: +4535452690

E-mail: phom@rh.regionh.dk

Dr P Homøe takes responsibility for the integrity of the content of the paper.

Competing interests: None declared 